40 (3) | 2011

Varia

La «comunidad» de Colalao y Tolombón (Argentina) hacia mediados del siglo XIX. Características de una institución en redefinición

La «communauté» de Colalao et Tolombon (Argentine) au milieu du $19^{e}$ siècle.

Caractéristiques d'une institution en redéfinition

The «comunity» of Colalao and Tolombón (Argentina) around the middle of $19^{\text {th }}$ century. Characteristics of an institution in redefinition

Lorena B. Rodríguez

(2) OpenEdition

Journals

Edición electrónica

URL: http://journals.openedition.org/bifea/1311

DOI: 10.4000/bifea.1311

ISSN: 2076-5827

Editor

Institut Français d'Études Andines

Edición impresa

Fecha de publicación: 1 diciembre 2011

Paginación: 495-509

ISSN: 0303-7495

Referencia electrónica

Lorena B. Rodríguez, « La «comunidad» de Colalao y Tolombón (Argentina) hacia mediados del siglo XIX. Características de una institución en redefinición », Bulletin de l'Institut français d'études andines [En línea], 40 (3) | 2011, Publicado el 01 junio 2012, consultado el 06 noviembre 2020. URL http://journals.openedition.org/bifea/1311 ; DOI : https://doi.org/10.4000/bifea.1311

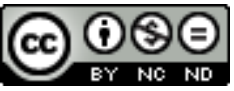

Les contenus du Bulletin de l'Institut français d'études andines sont mis à disposition selon les termes de la licence Creative Commons Attribution - Pas d'Utilisation Commerciale - Pas de Modification 4.0 International. 


\title{
La «comunidad» de Colalao y Tolombón (Argentina) hacia mediados del siglo XIX. Características de una institución en redefinición
}

\author{
Lorena B. Rodríguez*
}

\begin{abstract}
Resumen
El objetivo de este artículo es, desde una perspectiva antropológica e histórica, analizar algunas de las características que adquirió la comunidad indígena de Colalao y Tolombón (actual provincia de Tucumán, Argentina) hacia mediados del siglo XIX; esto es, observar quiénes la conformaban, cuál era el sistema de representación en vigencia, cómo se utilizaban y administraban los bienes de tal colectivo y, a la luz de estos datos, debatir y reflexionar acerca de los significados del término «comunidad» en un contexto de grandes cambios y redefiniciones sociopolíticas, económicas y étnicas, como lo es el de la transición de la etapa colonial a la republicana.
\end{abstract}

Palabras clave: Argentina, indígenas, comunidad, tierras, siglo XIX

\section{La «communauté» de Colalao et Tolombon (Argentine) au milieu du $19^{\mathrm{e}}$ siècle. Caractéristiques d'une institution en redéfinition}

\section{Resumé}

Dans une perspective anthropologique et historique, cet article cherche à analyser les caractéristiques qu'a revêtue la communauté indienne de Colalao et Tolombón (actuelle province de Tucumán, en Argentine) au milieu du 19e siècle. II s'agit de comprendre qui la composait, quel était le système de représentation en vigueur, comment les biens d'une telle collectivité étaient utilisés et administrés puis,

Universidad de Buenos Aires, Consejo Nacional de Investigaciones Científicas y Técnicas. La Porteña 45, (1406) CABA, Argentina. E-mail: rodriguezlo@hotmail.com 
à la lumière de ces données, de s'intéresser sur le sens du terme de «communauté» dans le contexte de grands changements sociaux, politiques, économiques et ethniques que représente la transition de l'époque coloniale àl'époque républicaine.

Mots clés : Argentine, indiens, communauté, terres, $19^{e}$ siècle

\title{
The «comunity» of Colalao and Tolombón (Argentina) around the middle of $19^{\text {th }}$ century. Characteristics of an institution in redefinition
}

\begin{abstract}
The aim of this paper is to analyze from an anthropological and historical perspective some of the characteristics acquired by the indigenous community of Colalao and Tolombón (current province of Tucumán, Argentina) around the middle of 19th Century.This is, this article considers who were part of the community, what the system of representation was practiced, how the goods of this collective unit were used and administered and, in the light of this data, to discuss and reflect on the meanings of the term «community» within the context of major changes and socio-political, economic and ethnic redefinitions, as was the case during the transition from the colonial era to the republian one.
\end{abstract}

Key words: Argentina, indigenous, community, lands, $19^{\text {th }}$ century

\section{INTRODUCCIÓN}

Entre 1839 y 1840, los apoderados de doña Juana Cornejo (y luego de don Manuel Paz) solicitaban a las autoridades tucumanas que se declarara por nulo e ilegal el nombramiento del protector de los naturales de Colalao y Tolombón, con quienes doña Juana tenía un añoso conflicto por linderos. Los argumentos de dichos apoderados para tal solicitud eran diversos. Por un lado, señalaban que el ser defendidos «gratuitamente» por un protector de indios implicaba un grave perjuicio no solo para doña Juana — expuesta a «ser incomodada con pleitos impertinentes»—, sino también para el erario público, en tanto la legislación indiana había previsto que quienes entablaran pleito bajo protectorado no debían pagar derecho de actuaciones ni hacer las presentaciones en papel sellado. Por otro lado, y más importante aún, determinaban que el «privilegio» de contar con un protector era cuanto menos injusto, ya que los indios — al haber sido exceptuados en 1811 de tributos y mitas - se encontraban a partir de ese momento en las mismas condiciones que cualquier hombre. Agregaban que antiguamente «tenían un protector pero en pos que formaban una comunidad que tenía cacique, un encomendero. Ya no la forman y por consiguiente ya no pueden tener otra protección que la 
que daba la ley a todos los demás ciudadanos «quienes son iguales en derechos y en obligaciones»1. En definitiva, los apoderados de doña Juana cuestionaban la existencia de la comunidad. La respuesta del protector de los naturales no se hizo esperar, señalando que la comunidad, tal como él la entendía, aún existía y que por lo tanto el protectorado debía mantenerse en vigencia. En primer lugar, diferenció a las comunidades, en general, de las de indígenas:

«Porque mientras tanto aquellas no son pobres, estas lo son y por esto es que el legislador quiso diferenciar las de los indios de las demás».

En segundo lugar, agregó:

«Puedo decir que ya no forma comunidad en razón a que está quitado el tributo, mitas, encomienda, yanaconazgo, servicio personal y cacicazgo, cierto, evidente; en razón a que aún todavía no se han dividido la única propiedad que entonces y ahora todavía existe, falso, porque el terreno que ellos habitan todavía está indiviso»?.

Entonces, en aquel contexto, ¿qué era una comunidad o qué se designaba bajo dicho término? ¿Coincidía con el antiguo pueblo de indios colonial o se trataba de una entidad totalmente nueva? ¿Cuáles eran sus características? Más aún ¿qué era lo que para unos y otros definía a una comunidad? Partiendo de estas interrogantes, se propone analizar algunas de las características de la comunidad de Colalao y Tolombón hacia mediados del siglo XIX; esto es, observar quiénes la conformaban, cuál era el sistema de representación en vigencia, cómo se utilizaban y administraban los bienes de tal colectivo y, a la luz de estos datos, reflexionar acerca del/de los significado/s del término «comunidad» en un contexto de redefiniciones sociopolíticas, económicas y étnicas, como lo es el de la transición de la etapa colonial a la republicana.

A tal fin, a partir de una perspectiva antropológica e histórica, se analizará principalmente una serie de documentos del Archivo Histórico de Tucumán (AHT), tanto de la Sección Administrativa como de la Sección Judicial, que refieren a unos litigios por tierras entablados —al menos desde el siglo XVIIIentre distintos vecinos y la comunidad, así como a otras causas judiciales que giraron alrededor de los denominados apoderados de la misma. Se completa el análisis con las revisitas de indios realizadas por los borbones entre fines del siglo XVIII y principios del siglo XIX, actualmente depositadas en el Archivo General de la Nación de Buenos Aires (AGN), y se utilizará también algunos datos encontrados en el Archivo Parroquial de Trancas (APT). Las lecturas de bibliografía, más allá del caso y la región de estudio, referida a la problemática de las comunidades indígenas de Bolivia y Perú tanto en el siglo XIX como en el presente, han constituido una base fundamental desde la cual repensar y problematizar este caso de análisis.

1 Archivo Histórico de Tucumán (AHT), Sección Judicial Civil (SJC), Caja 77, Expte. 1, Año 1840, f. 20v. Destacado en original.

2 AHT, SJC, Caja 77, Expte. 1, Año 1840, f. 23v. 


\section{EL CONTEXTO GENERAL: ENTRE LA COLONIA Y LA REPÚBLICA}

El paso del periodo colonial al republicano implicó una serie de transformaciones para las poblaciones indígenas americanas. Los pueblos de indios de las denominadas provincias del interior argentino que aún subsistían en esta etapa de transición sufrieron un verdadero impacto al implementarse - en las primeras décadas del siglo XIX - las políticas liberales propias del nuevo orden (extinción del tributo y las mitas, eliminación de la figura del cacique, entre otras). Si bien es cierto que estas medidas habrían apuntado a revertir la desigualdad socioeconómica y jurídica en la que se habían visto sumergidas dichas poblaciones durante la Colonia, las mismas no necesariamente dotaron a los indígenas de un status igualitario al resto de la población. Como señala Doucet (1993), las políticas dictadas por las autoridades revolucionarias de Buenos Aires nunca alcanzaron un carácter general ni se aplicaron de manera homogénea, dejando en manos de los gobiernos provinciales la tarea de resolver la «cuestión del indio».

Este escenario de carácter heterogéneo y el hecho de que solo recientemente se ha comenzado a profundizar en el análisis de las transformaciones atravesadas por las poblaciones indígenas de nuestra región entre la Colonia y la República, dificultan el planteo de un panorama acabado. En líneas generales, se puede decir que uno de los mayores problemas que debieron afrontar en las primeras décadas del siglo XIX los antiguos pueblos de indios coloniales fue el de las tierras. En el marco de los ideales liberales, centrados en el individualismo y en el paradigma de la propiedad privada y circulante, salieron a flote antiguos pleitos, produciéndose una nueva avanzada contra las tierras de comunidad. De todas formas, como concluyen Teruel \& Fandos (2009), durante la primera mitad del siglo XIX el peso de las continuidades parece haber demorado el proceso de privatización de tierras y contribuido, en parte, a la persistencia de algunas comunidades3; esbozando así un cuadro de situación que excede la imagen de la abrupta y total desaparición del indígena y de la institución comunal.

Para la jurisdicción tucumana, dentro de la cual se encuentra nuestro caso de análisis, ha quedado registro de seis conflictos por tierras entablados por pueblos de indios contra diferentes agentes (estatales o privados). Como señala López (2006), entre las décadas de 1820 y 1830, los gobernantes tucumanos compensaron a los miembros de sus facciones a través de la entrega de tierras declaradas como baldías (luego fiscales) y fue a través de este mecanismo que muchos de los pueblos de Tucumán se vieron despojados de sus tierras y se desarticularon finalmente como colectivo. Ahora bien, como puede observarse en el trabajo de López, el destino

3 A modo de ejemplo remitimos a una serie de recientes trabajos que, aunque planteando matices propios de las trayectorias y características de cada población y jurisdicción, reflejan tanto el problema de la avanzada contra las tierras colectivas como la persistencia de muchas comunidades a lo largo del siglo XIX. Véase al respecto De la Orden (2006) para Catamarca; Gil Montero (2002; 2008) para Jujuy; López de Albornoz \& Bascary (1998), López (2006), Fandos (2007a; 2007b) y Rodríguez (2009) para Tucumán; Tell (2010) para Córdoba; Teruel \& Fandos (2009) en un estudio comparativo de las jurisdicciones salteña, jujeña y tucumana; entre otros. 
que siguieron las tierras comunales y las propias comunidades de la jurisdicción tucumana estuvo lejos de componer un cuadro homogéneo pues, como en el caso de Colalao y Tolombón y de Amaicha lograron preservar sus propiedades y pervivir más allá de la segunda mitad del siglo XIX. A continuación se aborda inmediatamente el caso específico de este trabajo.

\section{ALGUNOS DATOS SOBRE COLALAO Y TOLOMBÓN}

Como resultado de las guerras calchaquíes4, finalizadas hacia 1665 , las poblaciones locales fueron trasladadas (o desnaturalizadas) a diversos lugares a manos de los conquistadores españoles. Así, los indígenas de Colalao y Tolombón 5 fueron encomendados y reasentados en el valle de Choromoros (jurisdicción tucumana)6. Este valle de altura media, ubicado al noroeste de la actual provincia de Tucumán y atravesado de norte a sur por el río Salí, es una subregión agroecológica con limitaciones climáticas e hídricas, pero que dispone de áreas (fundamentalmente la central) que revisten relevancia económica por el aprovechamiento agrícolaganadero, caracterizado por un mesoclima semiárido cálido (Garrido, 2005) (véase fig. 1).

Una vez instalados en Choromoros a los indígenas de Colalao y Tolombón les fueron asignadas por merced, tal como lo establecía la legislación indiana, unas tierras sobre la ladera oriental del Aconquija y luego, en 1679, ampliaron sus terrenos a través de la compra de la estancia denominada «Pusana». Así, a pesar de haber sido encomendados a distintas personas, haber constituido dos pueblos de indios diferenciados y haber mantenido cada uno de ellos estructuras políticas propias hasta fines del periodo colonial, convivieron en una misma unidad territorial y, en muchos casos, entablaron relaciones entre sí y mecanismos de

4 La penetración hispana en el valle Calchaquí fue muy particular debido a la resistencia ofrecida por las poblaciones locales. Así, la efectiva conquista de la zona se logró tras un intenso proceso de luchas — las denominadas guerras calchaquíes - que duraron más de 130 años y en las que hubo tres momentos de extrema virulencia. El primero de ellos (1534-1565) tuvo su epicentro en el sector central del valle y fue liderado por el cacique de Tolombón, Juan Calchaquí. El segundo (1630-1643) es el que se conoce como «gran alzamiento» y estuvo encabezado por el cacique Chalemín. El tercero (1656-1665) se inició con la llegada a Tucumán del andaluz Pedro Bohórquez quien, autoproclamado como el último descendiente de los incas, lideró un alzamiento general que continuó, incluso, luego de haber sido este apresado (Lorandi \& Boixadós, 1987-1988).

5 También los chuschagastas fueron reasentados en el valle de Choromoros (La Higuera) pero solo mantuvieron sus derechos hasta mitad del siglo XVIII cuando don Miguel Antonio Alurralde les usurpó las tierras, pasando entonces a la condición de arrendatarios (López, 2006).

6 Si bien la estructuración étnica y la territorialidad de estas poblaciones antes de la llegada de los colonizadores es un tema sobre el que aún debe profundizarse (véase Lorandi \& Boixadós, 1987 1988; López de Albornoz \& Bascary, 1998), aquí se retoma la historia de las mismas una vez instalados y encomendados en el valle de Choromoros. Siguiendo a Wachtel (2001) se entiende que fue a partir de estos procesos que se crean o recrean unidades étnicas (lo que después se conoce como «comunidades indígenas») cuyos límites empezaron a ser los de los pueblos de reducción. 


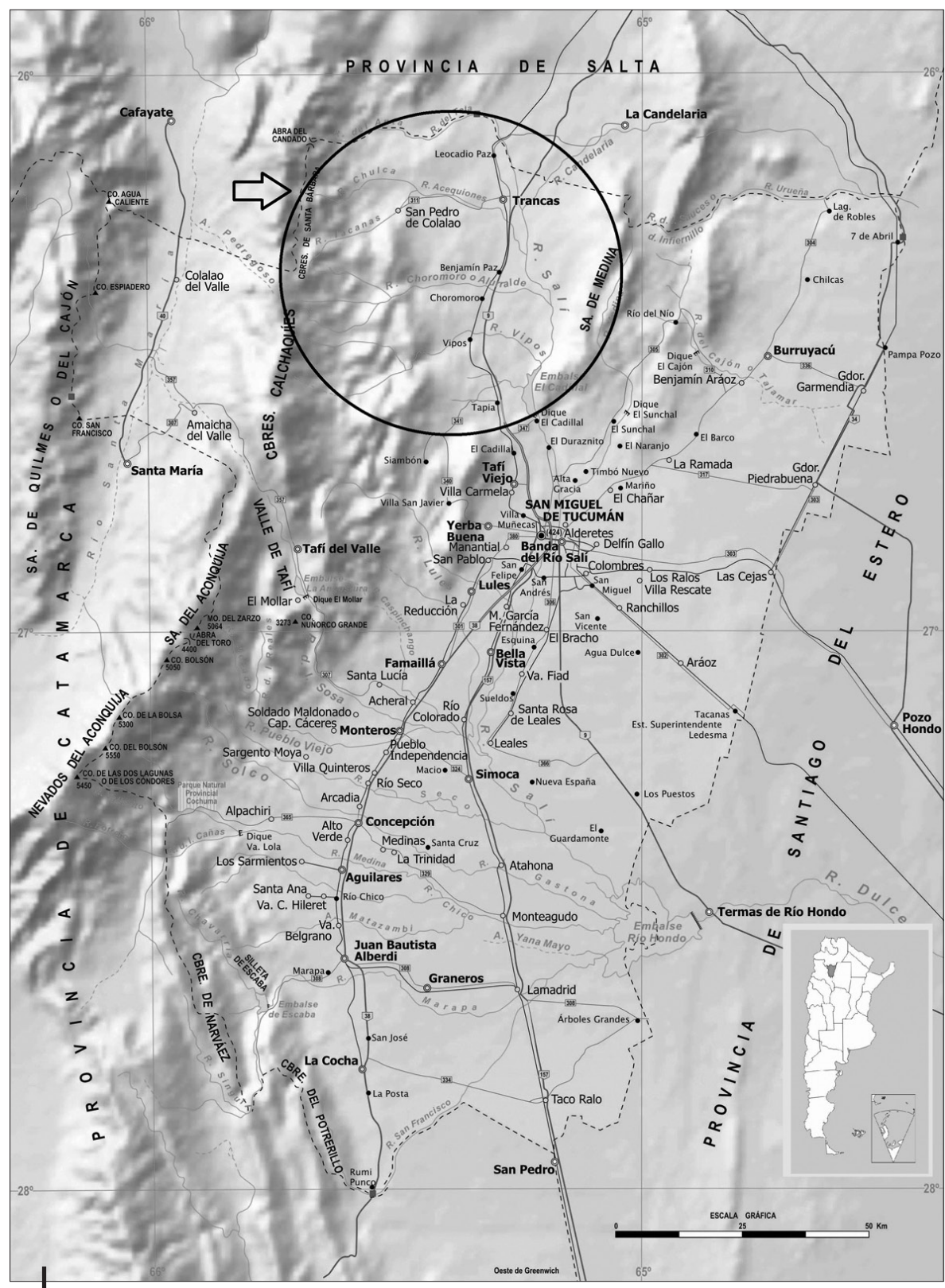

Figura 1 - Provincia de Tucumán y área de estudio

Fuente: Instituto Geográfico Nacional de la República Argentina 
adaptación comunes7. En las primeras décadas del siglo XIX, los documentos consultados - aunque en algunos casos todavía refieren a las comunidades o los pueblos de Colalao y de Tolombón - en su mayoría describen a la «comunidad» de Colalao y Tolombón como una entidad unificada.

Uno de los principales problemas a los que estos indígenas debían hacer frente fue el de las tierras. Según López de Albornoz \& Bascary (1998), el asentamiento tardío de dichas poblaciones en el valle de Choromoros, que desde el siglo XVII se encontraba ocupado por vecinos españoles, desencadenó una serie de litigios por las tierras que se extendió hasta avanzado el siglo XIX. Sin abundar en detalles se puede decir que, aunque los pleitos por linderos se inician ya en 1680 con don Pedro de Ávila y Zárate (antiguo encomendero del pueblo de Colalao), los conflictos más importantes eclosionaron con don Pedro Martínez de Iriarte (encomendero del pueblo de Tolombón) y con otros actores emparentados con este tronco familiar. Ya en el siglo XIX, un punto de inflexión en relación al derrotero seguido por los indígenas en torno a sus tierras comunales lo constituyó la venta de la estancia de Zárate realizada por doña Juana Fernández Cornejo (viuda del gobernador de Tucumán don Alejandro Heredia y descendiente de los Martínez de Iriarte) a favor de don Manuel Paz. El pleito heredado en 1839 por Paz con la comunidad de Colalao y Tolombón continuó hasta 1845 cuando se realizó el deslinde definitivo.

Como señala Fandos (2007a), en paralelo al proceso judicial con Paz emergen otras causas que involucran a distintos integrantes de la comunidad y que evidencian los conflictos internos que la atravesaban. Se trata de las disputas entabladas alrededor de los apoderados quienes, desde la década de 1830 aproximadamente, comienzan a representar a la comunidad frente al Estado y, fundamentalmente, a administrar los bienes de la misma. Es decir que, de alguna manera, estas cuestionadas figuras empiezan a tener peso en relación al destino de las tierras, así como también de la propia comunidad.

Las tierras de la comunidad de Colalao y Tolombón se mantuvieron indivisas hasta la década de 1870, cuando se inicia el proceso de fraccionamiento y de compraventa a título individual o entre «copropietarios» y compradores particulares. Para esa época, la propiedad comunal era ya un «condominio» en el que los titulares, poseedores en común de los terrenos pero con derecho a una «cuota parte», podían transferir y/o solicitar la división del bien condominial. La división y adjudicación definitiva de las otrora tierras comunales se realizó en el año 1903, reconociéndose así los derechos particulares sobre cada parcela en base a lo que cada propietario tenía ocupado (Teruel \& Fandos, 2009).

7 Las razones de los vínculos entre los indígenas de Colalao y Tolombón, más allá de compartir el espacio en Choromoros, probablemente se encuentren en antiguas interrelaciones étnicas, sociales, políticas y económicas desarrolladas en el valle Calchaquí, previo a su desnaturalización. Al respecto véase Lorandi \& Boixadós (1987-1988), López de Albornoz \& Bascary (1998). 


\section{3. ¿QUIÉNES CONFORMABAN LA COMUNIDAD A MEDIADOS DEL SIGLO XIX?}

Es difícil responder a la pregunta acerca de quiénes conformaban la comunidad de Colalao y Tolombón hacia mediados del siglo XIX, sin antes definir qué era la comunidad o qué entendían por tal los actores sociales de la época, en tanto se cree son aspectos que se imbrican indefectiblemente: ¿Quiénes integraban el colectivo o incluso cuáles eran los mecanismos de incorporación que delineaban o redibujaban, en parte, los límites o el significado de la institución «comunidad»? Basta, por ahora, con recordar las argumentaciones de los apoderados de doña Juana Cornejo y luego de don Manuel Paz y las de la comunidad para abordar el problema de quiénes conformaban tal entidad. De manera esquemática, se puede decir que mientras para los primeros la comunidad (para ellos desaparecida) se definía por la presencia de un cacique, de un encomendero y el pago del tributo (o sea de tributarios), para el protector de naturales y sus representados la comunidad (todavía en vigencia y por lo tanto con derecho de contar con un protector) era sinónimo de poseer las tierras de manera colectiva.

Estas dos líneas de argumentación presentan a la vez una solución y un problema a los fines de este apartado. Si se intenta conocer quiénes integran la comunidad siguiendo el criterio propuesto por el apoderado de Cornejo o Paz, es decir rastreando desde las últimas revisitas realizadas para el periodo colonial a los descendientes de quienes fueron empadronados en los pueblos de indios de Colalao y de Tolombón, se observa que hacia mediados del siglo XIX los límites de la comunidad no coinciden exactamente con los herederos de aquellos tributarios (ya sea que fueran originarios o forasteros).

Según Farberman (2001), resulta difícil determinar cómo se conformaba la población de los pueblos de indios finiseculares - y por lo tanto de sus límitesporque la población inscrita en los padrones no era exactamente la misma que residía en cada pueblo: no solo había personas que estaban empadronadas y que no vivían efectivamente allí, sino que constantemente había incorporación de gente (por diversos motivos y de diferentes status socioétnicos) que, en muchas ocasiones, no figuraba en los registros. Para el caso de Colalao y Tolombón, si bien López (2006) observó que una de las estrategias colectivas de supervivencia pudo haber sido el alto nivel de endogamia (aspecto que nos remite a pensar dicha entidad en torno a límites más o menos rígidos), hacia fines del siglo XVIII se observa cierta flexibilidad y aperturas (que, se entiende, se irá generalizando en la

8 López (2006) describe la endogamia a partir de las actas matrimoniales del curato de Trancas entre 1757-1766 y muestra que de los 18 casamientos registrados, ocho fueron entre indios e indias originarios de Tolombón, cuatro de Colalao, en dos casos los hombres fueron indios foráneos y en los restantes hubo casamientos exogámicos. Cabe aclarar que lo que se observa a partir de los padrones borbónicos no desestima lo observado por López. Primero, porque habría que hacer un análisis detallado a partir de los archivos parroquiales y, segundo, porque es tal vez el contexto 
primera mitad del siglo XIX) y que confirmaría la dificultad señalada por Farberman de aprehender y comprender el funcionamiento de tales entidades. En tal sentido, ya los padrones borbónicos finiseculares muestran un panorama bastante diverso dentro del pueblo: personas provenientes de lugares lejanos como el Perú, el Alto Perú, Atacama (en particular en el padrón de 1786), personas clasificadas bajo el rótulo de «forasteros sin tierra agregados a dicho pueblo» (en el padrón de 1791), casamientos con mujeres de distintos status socioétnicos (mulatas, zambas)9, entre otros. Panorama que, por distintas razones, se complejizará aún más en las siguientes décadas.

Ahora bien, como se ha señalado, aunque la utilización del criterio que podría denominarse fiscal-genealógico (es decir, hacer el seguimiento de los descendientes de quienes fueron empadronados a fines del XVIII) podría convertirse a priori en una solución o respuesta a nuestras interrogantes, resulta también en uno o en varios problemas. Así, se desprenden algunas dificultades de tipo metodológico que deben ser consideradas a la hora de analizar los datos. Por un lado, pues al centrarse nuestro foco en el periodo republicano ya no se dispone de listas de tributarios, sino de listas de propietarios o de individuos que componen la comunidad. Por otro, pues entre el último registro del periodo colonial (1806) y el primero del periodo republicano (1832) mediaron más de 25 años. Finalmente, no solo partimos de categorizaciones diferentes de la población (tributarios vs. propietarios) o del problema del vacío temporal, sino que los tipos de registros son bien diferentes (mientras en la revisitas constan edades o pueden reconstruirse las familias, en las listas de propietarios o de individuos de la comunidad analizadas solo constan nombres y apellidos individuales). En síntesis, se cuenta con documentación difícilmente comparable.

Aun si prosiguiéramos con este criterio de análisis, y más allá del problema o desafío que presentan nuestras fuentes, pronto se notaría - tal como se ha señalado- que las listas disponibles para la primera mitad del siglo XIX no coinciden plenamente con las listas de empadronados. Fundamentalmente, lo que se ha podido observar es que a medida que transcurren los años van registrándose nuevos apellidos de manera incremental10. Así, por ejemplo, en la «nómina de propietarios de Colalao y Tolombón y padres de familia» de 1832 cuyo número ascendía a 57 propietarios, fueron registradas ocho personas con apellidos nunca inscritos en las revisitas

finisecular (con los cambios relativos a la redefinición del poder de las autoridades étnicas, el paso de la tributación de encomiendas a cabeza del Rey, el aumento generalizado de población, el fenómeno de las migraciones, etc.) lo que explica la diferencia. Incluso, es posible pensar — tal como lo observa Farberman (2001) para el caso de los pueblos de indios de Soconcho a fines de la Colonia- que la endogamia matrimonial no era contradictoria con las uniones con personas externas a la comunidad, en tanto las mismas no eran dejadas al azar, sino que formaban parte de un sistema estructurado y consensuado por todo el colectivo.

9 AGN, Revisita de San Miguel de Tucumán, Años 1786 y 1792, Sala XIII 17-2-1, Leg. 2, Libros 3 y 6 ; Revisita de San Miguel de Tucumán, 1806, Documentos Diversos, Leg. 32.

10 Si bien este recorte metodológico resulta problemático porque, en muchos casos, se trata de apellidos «comunes» y de una gran dispersión, parece igualmente ser indicativo de las transformaciones que estaban atravesando y un buen generador de hipótesis de trabajo. 
(un $14 \%$ )11. En la elección de apoderado realizada en julio de 1843 entre los 38 propietarios presentes se registraron 11 personas con apellidos «nuevos» (un 28,9\%), de los cuales 7 no habían aparecido en 183212. Luego de una nueva elección de apoderado realizada en diciembre de 1843 se presentaron ante el juez partidario 46 propietarios, 13 de los cuales tenían apellidos no registrados en las revisitas coloniales $(28,2 \%)$, y de ellos 5 no se habían registrado hasta el momento13. Finalmente, en 1845 se realiza una nueva votación para elegir apoderados y se cita a todos «los individuos que componen la comunidad de Colalao y Tolombón» 14 . De las 67 personas que emiten su voto, 28 individuos tenían un apellido no registrado en los padrones finiseculares $(41,7 \%)$ y de esos 28 , seis nunca habían aparecido previamente. En síntesis, como señala Fandos (2007a), hacia mediados del siglo XIX aún persiste un grupo importante de apellidos heredados de la Colonia (Goya, Senardo, Guaiman, entre otros); sin embargo, también aparecen apellidos «nuevos» que exceden las listas de los padrones borbónicos, que nos dan una pista para conocer quiénes podrían formar parte del colectivo, a la vez que nos acercan a posibles mecanismos de «incorporación». En relación a estos mecanismos es probable que el matrimonio haya continuado siendo una de las vías de acceso a la comunidad; algunos datos dispersos en los expedientes judiciales consultados nos orientan hacia esa interpretación15.

De todas maneras, un aspecto interesante que nos devela el seguimiento de apellidos $y$, en algunos casos, de personas particulares es el que refiere al lugar de los arrenderos dentro de la estructura de la comunidad. Según Fandos (2007b), el incremento poblacional que ella observa durante el siglo XIX en la zona podría explicarse en la continuidad, fundamentalmente desde el periodo tardocolonial, de la recepción de migrantes. Asimismo, la autora relaciona esta tendencia ascendente de población con la posibilidad de arrendar las tierras de la comunidad y la figura de los arrenderos, destacando el peso que este fenómeno habría tenido para la comunidad. Por supuesto, y en relación al tema específico de este apartado, la presencia de arrenderos no demuestra directamente que estas personas hayan pasado a formar parte del colectivo. Aunque, como en el caso que desarrollaremos a continuación y el de otros sobre los que no se puede ahondar

11 AHT, Sección Administrativa (SA), Vol. 40, Tomo II, Año 1832, fs. 177-178. Para ese mismo año (1832) se cuenta también con un «listado de los naturales del pueblo de Colalao» (AHT, SJC, Caja 88, Expte. 20) que no coincide completamente con el listado anterior. Para trabajar el tema de los apellidos nos hemos centrado en el listado de la Sección Administrativa, en tanto resulta más completo e incluye mujeres y niños.

12 AHT, SJC, Caja 80, Expte. 17, Año 1843, fs. 4 a 5v.

13 AHT, SJC, Caja 80, Expte. 17, Año 1843, fs. 71v a 72v.

14 AHT, SJC, Caja 269, Expte. 9, Año 1845, fs. 1v a 4v.

15 Para confirmar esta práctica, se necesitaría realizar un estudio específico a partir de los archivos parroquiales. Es interesante notar que si bien se desprende de los expedientes judiciales del siglo XIX el hecho de que son los hombres los que se incorporan a la comunidad mediante el matrimonio, en los padrones finiseculares también parecen haberse integrado a la entidad mujeres procedentes de otros lugares y de distintos status socioétnicos. Resta, como señalamos, un análisis específico al respecto y de larga duración. 
aquí, podría ser indicador de una posible vía de incorporación. El ejemplo de Enrique Cabrera ilustra lo que queremos señalar. Uno de los primeros registros de este individuo data del año 1840 cuando, a raíz del pleito por tierras entablado con don Manuel Paz, ofició de testigo en la causa. En esa ocasión declaró a favor de los «indios», asegurando que los conocía hacía 19 años y que los terrenos les pertenecían16. En la lista de arrenderos presentada en 1844 por Mariano Córdoba, al momento de rendir cuentas de su desempeño como apoderado y administrador de la comunidad, también quedó registrado Enrique Cabrera17. En 1845, en ocasión de la reunión «de todos los individuos de la comunidad» con el fin de elegir apoderados, Enrique Cabrera participó de la elección pero no solo presenciándola o firmando por quienes no sabían hacerlo, sino votando él mismo por el/los candidato/s y siendo votado, a su vez, como posible apoderado18. O sea, se entiende, como miembro de ella. No se descarta, por supuesto, que su incorporación haya sido acompañada de un casamiento, aunque los datos que se han podido rastrear en los registros parroquiales no indican claramente que esa haya sido la vía directa de acceso a la comunidad19. Tampoco queda completamente claro si fue en calidad de propietario que Cabrera pasó a ser un «individuo de la comunidad», aunque esta es una posibilidad. Sí se cree que el hecho mismo de participar de la elección de apoderado es muy significativo y da cuenta de la integración de este individuo al colectivo.

Este tema de los arrenderos nos devuelve al segundo de los criterios planteado al iniciar este apartado. ¿Qué pasaría entonces si ensayáramos tomar como criterio aquel que señala que ser miembro de la comunidad es sinónimo de ser propietario de las tierras colectivas? En principio, se diría que esta es una buena ecuación (miembro=propietario) para determinar los límites de la comunidad. Sin embargo, el ejemplo del arrendero Cabrera nos hace reflexionar acerca de la temática. Por un lado, en tanto nos impulsa a repensar el término «propietario» en dicho contexto; por otro lado, porque nuevamente nos invita a preguntarnos acerca de los mecanismos por los cuales los individuos pasaban a formar parte de la comunidad. Probablemente, arrendar por años tierras de la comunidad facilitaba la incorporación de distintas personas a dicha entidad, incluso estrechándose los lazos a través del matrimonio20. Por supuesto, tal como muestran nuestros datos,

16 AHT, SJC, Caja 77, Expte. 1, Año 1840, f. 172v.

17 AHT, SJC, Caja 80, Expte. 17, Año 1843, fs. 56 y 56v, 91 y 92. Si bien en el documento se detallan los arriendos correspondientes al periodo en que Córdoba cumplía con las funciones de apoderado y administrador (1839-1844), queda claro que ya desde antes de 1839 Cabrera arrendaba tierras de la comunidad.

18 AHT, SJC, Caja 269, Expte. 9, Año 1845, fs. 1v a 4.

19 Se ha encontrado dos casamientos de Enrique Cabrera. El primero, en el año 1823, con Salomé Agüero (vecina de Chulca) quien no parece ser de la comunidad. El segundo, en 1844, con Marta Fernández, de quien no se puede deducir si pertenecía o no a la misma (APT, Libro de Matrimonio, Vol. V, f. 92; Vol.VII, f. 106v). Disponible en: www.familysearch.org.

${ }^{20}$ Como señala Cosamalón Aguilar (1999) en su análisis sobre las prácticas matrimoniales de la parroquia de Santa Ana (Lima) entre los años 1795-1820, son los «espacios de convivencia» los que construyen el mundo de las relaciones sociales y, por ende también, de las matrimoniales. 
no todos los arrenderos pasaron a integrar las listas de propietarios o individuos de la comunidad pero - en algunos casos y mediando ciertas condiciones o, incluso, negociaciones - el hecho mismo de compartir el espacio, los problemas o los intereses pudo haber funcionado como un posible canal de acceso a la misma21. Después de todo, como señalaba don Manuel Paz en 1844 al intentar desacreditar a los testigos presentados por parte de la comunidad:

«Los testigos que han declarado a favor de los indios merecen el menor crédito tanto porque todos son de los mismos indios o arrenderos o que están viviendo o disfrutando del terreno en disputa, cuanto porque no dan razón de lo dicho... cuando aseguran que saben lo que declaran porque viven en el lugar, es decir en las mismas tierras de los indios y como arrenderos no merecen créditos pues que son interesados en la causa. Tienen el mismo interés que los principales que litigan porque saben que perdiendo los indios el pleito tendrán que desocupar el terreno»22.

Asimismo, en relación a la ecuación propietario $=$ miembro de la comunidad es interesante notar que en 1832, con pocos días de diferencia, se elaboraron dos listados de personas relativos a la comunidad de Colalao y Tolombón. El primero de ellos quedó inscrito en el Archivo Histórico de Tucumán como «Nómina de propietarios de Colalao y Tolombón y padres de familia»23 y había sido realizado por pedido del gobernador Heredia. El segundo, rotulado como «Lista de los naturales del pueblo de Colalao»24, había sido confeccionado por parte de la comunidad para formalizar la sujeción de 45 personas a don Pedro José Goya y a Valentín Senardo. Lo importante a destacar aquí es que si bien en líneas generales las listas coinciden, no son exactamente iguales. Hay personas que figuran en el listado de propietarios pero no están en el de naturales y viceversa. Estas diferencias nos empujan nuevamente a repensar el binomio propietario-integrante de la comunidad.

Para finalizar, y sin dar aún una respuesta definitiva acerca de quiénes conformaban la comunidad o por dónde pasaban los límites de la misma a mediados del siglo XIX, queremos desarrollar un ejemplo que da cuenta de la dificultad que tenemos de asir a dicha entidad. Se trata del conflicto desatado en 1843 entre Bernardo Goya y Mariano Córdoba a raíz de que el primero solicite ante las autoridades provinciales que Córdoba fuera removido de su cargo de apoderado y administrador de la comunidad25. Las aristas del pleito y los argumentos presentados por una y otra parte son diversos 26 . Aquí nos centraremos en la forma en que ambos actores

21 Los datos presentados por Fandos (2007b) refuerzan, a nuestro entender, esta interpretación. La autora describe cómo algunos de los que accedieron a la tierra a través del arriendo en las décadas de 1830 y 1840 y que reforzaron sus lazos con la comunidad a través del matrimonio, constituyeron familias a las que posteriormente se les reconocieron derechos sobre tierras cuando se realizó el fraccionamiento definitivo en 1903.

22 AHT, SJC, Caja 77, Expte. 1, Año 1840, fs. 203v y 204. El destacado es nuestro.

23 AHT, SA, Vol 40, Tomo II, Año 1832, fs. 177-78.

24 AHT, SJC, Caja 88, Expte. 20, Año 1849. Agradezco a la prof. Beatriz Vallejo el haberme facilitado tan gentilmente este expediente.

25 AHT, SJC, Caja 80, Expte. 17, Año 1843.

26 Un detalle del conflicto puede verse en Fandos (2007a). 
se presentan y legitiman o deslegitiman la pertenencia a la comunidad. En primer lugar, es importante decir que mientras Goya aparece siempre en los registros como «indio originario de», Córdoba lo hace como «vecino de». En segundo lugar, uno de los tantos argumentos de Goya contra Córdoba es que este último es un «advenedizo y extraño», señalando que como tal «se nos ha entrometido a tomar parte en nuestros negocios y disfrutar de nuestras tierras»27. Córdoba, a su vez, responde a la acusación de Goya en los siguientes términos:

«Este [Goya] me llama intruso en el pueblo y le preguntaré yo si mi esposa es oriunda del mismo pueblo y si yo debo representar su acciones y derechos como legítimo marido»28.

Es decir, si bien ambos dicen ser parte de la comunidad, sus trayectorias de pertenencia parecen ser distintas. Goya se presenta como indio originario y detenta un apellido que no solo figuraba en los padrones borbónicos, sino que probablemente pertenece al tronco familiar de Pedro José Goya (cacique colonial y figura importante en el desarrollo del pleito por las tierras incluso también en años republicanos). Córdoba, en cambio, estaba «avecindado» en Colalao pero era oriundo de Belén (Catamarca)29. Su puerta de acceso a la comunidad, según sus declaraciones, se había producido por ser «legítimo esposo de doña Gabriela Vázquez oriunda de dicho pueblo»30. Es interesante notar que, si bien el casamiento de Córdoba se había producido en 1820, pudiéndose fechar su incorporación en ese momento, en un expediente de 1832 se cita a Córdoba como testigo en el juicio contra Pedro José Goya y Valentín Senardo por malversación de fondos, pero diferenciando su declaración de la de los propietarios del terreno de Colalao «a quienes corresponde el arriendo»31. Pareciera que, en ese momento, no se le considera parte de la comunidad; aspecto que nos remite a pensar nuevamente en la cuestión de los límites de la entidad y su flexibilidad.

En síntesis, es difícil determinar con precisión quiénes pertenecían a la comunidad de Colalao y Tolombón en este periodo de transición o cuáles eran los mecanismos de incorporación a la misma. Como vimos, ni el criterio genealógico-fiscal, ni el criterio referido a ser propietario de las tierras colectivas son completamente válidos para repensar dichas cuestiones. Como lo han señalado diversos autores, esta es una etapa de grandes cambios pero también de permanencias, de tensiones entre lo nuevo y lo viejo. En los próximos apartados se retoman estas tensiones con el fin de reflexionar sobre distintas aristas y problemas referidos a la comunidad de Colalao y Tolombón.

27 AHT, SJC, Caja 80, Expte. 17, Año 1843, f. 12v.

28 AHT, SJC, Caja 80, Expte. 17, Año 1843, f. 9v.

29 APT, Libro de Matrimonios, Vol. IV, f. 34. Disponible en: www.familysearch.org.

30 AHT, SJC, Caja 80, Expte. 17, Año 1843, f. 16. Goya, igualmente, señala en el expediente que la mujer de Córdoba «tampoco tiene derecho alguno a nuestro pueblo» (f. 12v). Queda claro, igualmente, que la incorporación al mismo, vía matrimonio, era aceptada.

31 AHT, Sección Judicial Criminal (SJCr), Caja 56, Expte. 6, Año 1832. Agradezco a la prof. Beatriz Vallejo el haberme facilitado tan gentilmente este expediente. 


\section{DE CACIQUES, PROTECTORES Y APODERADOS DE LA COMUNIDAD}

La corona española, reconociendo la autonomía de las poblaciones indígenas, instauró en América — desde el siglo XVI— un sistema de gobierno indirecto en el cual los «señores naturales» o curacas cumplieron diversas funciones (en particular, como representantes de los indígenas e intermediarios entre estos y el Estado colonial) y pervivieron, en algunos casos, hasta fines del periodo colonial. El inicio del periodo republicano supuso, entre otras cosas, la abolición de la figura del cacique32 e impulsó a las comunidades indígenas que aún subsistían a buscar nuevas formas de representación. De esta manera, si durante la Colonia fue generalmente el cacique (junto con el protector de naturales33) el que representó a la comunidad ante el Estado colonial, en el nuevo contexto serán los denominados apoderados quienes ejercerán esta función frente a las autoridades republicanas. Evidentemente, un cambio fundamental se había puesto en marcha. En el sistema jurídico de antiguo régimen, los caciques (y hacia el final del periodo colonial los alcaldes) representaban de forma colectiva y natural a su comunidad, sin necesidad de que un documento específico los reconociera formalmente. A partir de la instauración del sistema republicano, centrado en el individuo y basado en la representación personal frente a la ley, se desconoció a esos representantes naturales y colectivos (por considerarlos ahora ciudadanos individuales) y paulatinamente se fue exigiendo una nueva representación —basada en la ley y la palabra escrita - que sería condensada en la figura del apoderado (Soux, 2005; Mendieta Parada, 2006).

Específicamente para el caso de Colalao y Tolombón, quienes han Ilamado la atención sobre esta «nueva institución» han sido López de Albornoz \& Bascary (1998), destacando de ella el hecho de ser colegiada (generalmente más de un apoderado) y electiva. Estos dos elementos nos remiten a una serie de preguntas acerca de sus vínculos, semejanzas o diferencias con antiguas prácticas de la comunidad. Tal como lo señalan las autoras que acabamos de citar:

32 Se ha simplificado aquí un largo proceso de casi tres siglos de transformaciones de la institución cacical, por no hablar del periodo previo a la llegada de los españoles. Siguiendo a Farberman (2005), puede decirse que en este proceso hubo dos momentos claros de inflexión. El primero de ellos, enmarcado en las reformas toledanas de la década de 1570, implicó la redefinición del poder de los «señores naturales» a raíz de la instauración paralela de autoridades electivas: los alcaldes. El segundo de ellos, a caballo entre las reformas borbónicas y las consecuencias derivadas de la rebelión de Tupac Amaru (1780), supuso la declinación de la figura cacical. El problema de las autoridades indígenas a fines del periodo colonial ha sido ampliamente debatido. Los autores coinciden, aunque con matices según las regiones o los casos estudiados, en que en dicho periodo se produjo una paulatina pérdida del poder de los caciques hereditarios y un mayor protagonismo de las autoridades electivas o «por aclamación». Entre otros, véase al respecto Sala i Vila (19921993); O’Phelan (1997); Serulnikov (2004).

33 En tanto en el derecho indiano los indios eran considerados como menores, rústicos y miserables, además del curaca que hacía las veces de representante frente al Estado, el protector de naturales debía defenderlos en las distintas instancias judiciales. Sobre este tema véase Levaggi (1990). 
«[e]s probable que esta normativa sea nada más que la explicitación por escrito de la vieja tradición de la comunidad en cuanto a la administración de su propiedad» (López de Albornoz \& Bascary, 1998: 106).

Sin poder responder aún a estos cuestionamientos se describe, a continuación, algunas de las características que asumió la institución en nuestro caso de estudio. Hasta principios del siglo XIX fueron los caciques y alcaldes (acompañados por los protectores de indios) de Colalao y Tolombón quienes llevaron adelante los pleitos y se ocuparon de distintas tareas relativas a la administración de la comunidad. En la década de 1830 empezó a delinearse una transformación. En el contexto del juicio criminal iniciado por el gobernador de la provincia Alejandro Heredia contra Pedro José Goya y Valentín Senardo por malversación de los fondos de arriendo, se realizó lo que se entiende como un primer intento de formalizar a estas figuras y un antecedente para la posterior aparición de los apoderados. Así, la «lista de los naturales del pueblo de Colalao que son comprometidos en la unión y junta que se formalizó para estar sujetos al que hace cabeza para todo lo que ofrezca en adelante»34 — realizada en septiembre de 1832 y encabezada por Pedro José Goya y Valentín Senardo- no solo constituyó un compromiso de estos últimos para «ayudar a nuestros ascendientes ya referidos», sino una vía para legalizar, dentro de los nuevos cánones que estaban estableciéndose, a Goya y a Senardo y, por supuesto, a las funciones cumplidas por estos dentro de la comunidad. Así, fue recién el 28 de febrero de 1839, que emergió puntualmente la figura de apoderado de la comunidad. Ese día se realizó la elección formal de los primeros apoderados de Colalao y Tolombón, resultando seleccionados don Silverio Sardina, don Mariano Córdoba y don Silverio Fernández35. A partir de ese momento, se realizaron varias elecciones en las que el número de apoderados fue oscilando generalmente entre dos y cuatro. Es interesante al respecto lo que decía Córdoba:

«Todos en montón se reunieron para entresacar entre ellos tres individuos de aquellos que les pareció que podrían desempeñar estas funciones... Esta operación pudieron haberla hecho en otras personas que no correspondiesen ni perteneciesen a los mismos pueblos y pudieron también haberla hecho en una sola persona. Desde que esta comunidad se despojó y renunció en estas personas, toda aquella autoridad y privilegios de que gozaban recayeron en sus apoderados» 36 .

De este fragmento se retoman dos ideas principalmente. Por un lado, el hecho de que expresamente la comunidad tomó la decisión de elegir a varios apoderados y que no recayera esta función en una sola persona. En tal sentido, en 1845

\footnotetext{
34 AHT, SJC, Caja 88, Expte. 20, Año 1832, f. 6.

35 AHT, SJC, Caja 80, Expte. 17, Año 1843, f. 77. En realidad, se había realizado una reunión previa para elegir apoderados en la que, además de Sardina, Córdoba y Fernández, había sido seleccionado Bernardo Goya. Sin embargo, según lo referido por Córdoba, la comunidad habría desechado a este último quedando solo los tres antes nombrados (f. 16v).

36 AHT, SJC, Caja 80, Expte. 17, Año 1843, f. 17.
} 
cuando dos de los apoderados habían fallecido (Sardina y Córdoba) y quedaba en funciones solo uno de ellos (Fernández), se pedía una nueva elección para acompañar en las tareas a quien había quedado a cargo, por ser:

«Gravoso el desempeño de su oficio y peligrosa su soledad en razón a que los mismos miembros de la comunidad (algunos en pequeño número) no dejan continuamente de querer y ejecutar algunas tentativas contra los derechos del cuerpo» 37 .

Por otro lado, resalta la idea de que quienes devienen en apoderados corresponden y pertenecen a la comunidad. Como vimos en el apartado anterior, no es fácil determinar cuáles eran los parámetros para considerar o no a las personas como parte de dicha entidad. Resulta interesante notar que la mayoría de quienes fueron elegidos como apoderados no poseían apellidos «tradicionales» (en el sentido de no ligados al núcleo de apellidos que aparecían en los padrones borbónicos) 38 y se distinguían por algunas características particulares. Desarrollaremos, como ejemplo, el caso de don Silverio Sardina. Este era hijo de don Mariano Sardina (natural del valle de Tarija y avecindado en El Brete, Trancas) y de doña Juana Cabezas (natural de El Brete) ${ }^{39}$, quienes poseían tierras compradas en dicho lugar, colindantes con las de la comunidad40. Según se desprende de los expedientes, don Silverio habría ingresado a la comunidad, al igual que Córdoba, a través del matrimonio. Así, en una de las primeras actuaciones como apoderado frente a las autoridades provinciales se presentaba como «don Silverio Sardina, marido de doña Dolores Álvarez, descendiente de los antiguos caciques de Tolombón y Colalao»»11. En ocasiones, don Silverio se presentaba también como «capitán de la segunda [compañía] del primero de coraceros graduado de sargento mayor»; es decir, que formaba parte del ejército tucumano 42 y, fundamentalmente, sabía leer y escribir.

37 AHT, SJC, Caja 269, Expte. 9, Año 1845, f. 1.

38 De esta manera, en 1839 se nombran como apoderados a Silverio Sardina, Mariano Córdoba y Silverio Fernández. En diciembre de 1843, a fin de cumplir con la tarea específica de tomarle cuentas a Córdoba como resultado de su conflicto con Goya, se designan como apoderados a Estanislao Romano, Manuel Guaiman y Luis Tejerina (AHT, SJC, Caja 80, Expte. 17, Año 1843). En 1845 resultan electos Silverio Fernández (que permanecía desde la primera elección), José María Bellido, José Gabriel Campero y Manuel Guaiman (AHT, SJC, Caja 269, Expte. 9, Año 1845). En 1848 es elegido Bernardo Goya (AHT, SJC, Caja 77, Expte. 1, Año 1840; Caja 88, Expte. 20, Año 1849) y nuevamente en 1854 con el fin específico de acudir a las autoridades tucumanas para que se realizara una nueva elección de apoderado. Finalmente, en 1855 es elegido Ambrosio Columbres, vecino de la ciudad de San Miguel de Tucumán (AHT, Caja 93, Expte. 3, Año 1855). Los apellidos Sardina, Córdoba, Tejerina, Campero y Columbres, no figuran en los padrones borbónicos.

39 APT, Libro de Matrimonio, Vol. IV, f. 1.

40 AHT, Caja 290, Expte. 1, Año 1839, f. 31

41 AHT, Caja 290, Expte. 1, Año 1839, f. 45. En los expedientes que hemos consultado no figura el apellido Álvarez ligado a ningún tipo de autoridad étnica en tiempos coloniales. En el acta de matrimonio de Sardina con Álvarez del año 1829, ella figura como hija natural de Isabel Álvarez (APT, Libro de Matrimonios, Vol. VII, f. 23).

42 Del contexto se desprende que participaba de las milicias convocadas por el gobernador de Tucumán Bernabé Piedrabuena, como parte de la «Coalición del Norte» (1839-1841) contra el «orden rosista». Sobre este tema véase Macías (2007). Esta participación «para salvar a la patria» era utilizada por Sardina como argumento para que la comunidad pudiera contar con un defensor de pobres (al 
Como otros apoderados, Sardina actuaba en relación a diferentes aspectos de la comunidad. Básicamente administraba los bienes de la misma (arrendaba los terrenos, llevaba las cuentas de ingresos y egresos, buscaba dinero para solventar distintos gastos) y representaba a sus integrantes frente al Estado provincial; en particular, en lo relativo a los pleitos por tierras que la comunidad sostenía desde el periodo colonial. Es interesante resaltar que Sardina aprovechaba sus vínculos (de parentesco o de amistad) para conseguir el dinero necesario a fin de cumplir con las deudas de la comunidad que, generalmente, eran producto de los engorrosos trámites y presentaciones relativos a los vericuetos judiciales. Así, en una carta fechada en julio de 1841 en Colalao, Sardina le solicitaba a don Benigno Vega el préstamo de una suma de dinero:

«Mi más estimado pariente, el dador de esta es don Mariano Córdoba a quien mando a darle una incomodidad a Ud., la cual es que por hallarme sumamente en grandes apuros para que me hiciera el cariño de suplirme 25 pesos que por estar a concluir un pleito de un terreno y en ello sale a mi favor la sentencia y necesito para esto este favor de Ud. Si acaso tiene como pues, esta carta le servirá de documento. A más que Córdoba es mi misma persona y le otorgará obligación a pagarle el rédito y todos sus suplementos hasta el mes de mayo de la presente» 43 .

Tal como ha señalado Mendieta Parada (2006) para el caso de Bolivia, los apoderados parecen haber sido seleccionados por varias razones: saber leer y escribir, tener conocimiento o experiencia en las cuestiones legales $y$, fundamentalmente, disponer de una red de relaciones, en particular, con los miembros de los poderes locales. Sardina, en nuestro caso, parece haber cumplido con estos requisitos, logrando un lugar destacado dentro de la comunidad así como también dentro de la estructura de los apoderados44, en tanto aparece en los registros como el principal o cabeza. Córdoba se refería a él de esta manera:

«[d]e los cuatro nombrados ha fallecido el principal que lo era el Coronel don Silverio Sardina, por su fallecimiento es verdad que he seguido yo haciendo cabeza en esta comisión»45.

En términos más generales y en cuanto a la forma en que se realizaban las elecciones, es importante señalar que las mismas debían efectuarse en presencia del juez del distrito (en este caso Trancas) o, en su defecto, de una comisión de vecinos de «reconocida probidad», que no tuvieran parentesco con los de la comunidad, que supieran leer y escribir y a los que se les adjudicaba poder para «reprimir cualquier desorden que pudiera haber»46. Así, debían reunirse todos los

haber sido eliminada la figura del protector). También, a causa de esta misma participación, sus opositores acusaban al «salvaje Sardina» de querer «destruir la Santa Causa de la Federación».

43 AHT, SJC, Caja 80, Expte. 17, Año 1843, f. 49 y 49v. Otra persona a quien Sardina había pedido dinero en más de una oportunidad era Cirilo Córdoba con quien tenía un «lejano parentesco» y quien, además de testificar en varias ocasiones a favor de la comunidad, arrendaba tierras a la misma.

${ }^{44}$ Fandos (2007b) sugiere, incluso, que constituían una verdadera «elite» diferenciada del resto que, a través de cuidadas relaciones, reforzaban su lugar dentro de la comunidad.

45 AHT, SJC, Caja 80, Expte. 17, Año 1843, f. 9.

46 AHT, SJC, Caja 269, Expte. 9, Año 1845, f. 1. 
individuos (tanto hombres como mujeres) y emitir sus votos, los que refrendaban a través de la firma. El tiempo que mediaba entre una y otra elección dependía de distintos factores: muerte de los apoderados, denuncia de malversación de fondos y necesidad de reemplazo; incluso, se observa la designación de apoderados para cumplir tareas específicas. Por ejemplo cuando en 1843 fueron elegidos tres apoderados (don Estanislao Romano, don Manuel Guaiman y don Luis Tejerina) para que «bajando a la capital, pidan cuentas al apoderado don Mariano Córdoba» pero especificando que exclusivamente el poder otorgado era para el fin citado.

Ahora bien y para cerrar este apartado nos preguntamos: ¿Estas formas de elección y de representación tienen puntos de contacto o semejanzas con prácticas coloniales y antiguas figuras de autoridad étnica o se trata, en realidad, de formas más «modernas», totalmente novedosas? Por cierto, en el estado en que se encuentra la investigación no podemos responder a ciencia cierta a esta interrogante. Sin embargo, el ejemplo antes citado del conflicto entablado entre Bernardo Goya y Mariano Córdoba puede constituirse en una base desde la cual repensar esta problemática. Se ha visto ya las trayectorias de estos dos actores, las formas diferenciadas de presentación y los argumentos por los cuales cada uno acreditaba o desacreditaba la pertenencia a la comunidad. De esta forma, si el principal argumento de Goya giraba en torno a demostrar lo advenedizo y extraño que era Córdoba, éste último no discutía la pertenencia de Goya a la comunidad pero sí ponía en duda su representación del colectivo:

«En su pedimento [Goya] dice por mi y a nombre de mis compartes y pregunto: ¿cuáles son sus compartes? ¿Con qué documento lo acredita?... ¿ ¿ónde está el poder de su padre que lo autorice?»47.

Lo que intentaba decir Córdoba es que ya no tenía validez una representación «a nombre de» o «por todos», si no mediaba un poder firmado por todos los integrantes de la comunidad. Es decir, que un individuo ya no podía encarnar la voluntad de su comunidad naturalmente si no existía la expresa voluntad de los integrantes (por supuesto, plasmada en la palabra escrita) de que esto así ocurriera. En definitiva, lo que el ejemplo de Goya y Córdoba pone sobre el tapete son, una vez más, las tensiones emergentes en un contexto de transición en el que los límites de la comunidad y las formas de representación de la misma estaban transformándose lentamente. En el apartado siguiente se analizarán otros elementos que se encuentran en esa misma sintonía y que, finalmente, nos permitirán reflexionar sobre la comunidad de Colalao y Tolombón.

\section{SOBRE LA PROPIEDAD COLECTIVA DE LA TIERRA Y SU ADMINISTRACIÓN}

La comunidad de Colalao y Tolombón no puede pensarse si no se toma en cuenta el problema de la tierra. No por entender a priori que comunidad es sinónimo de 
propiedad colectiva, sino porque desde la época colonial se observa en nuestro caso un esfuerzo por mantener, recuperar o proteger este recurso hasta bien entrado el siglo XIX. Ahora bien, ¿qué nos dice este carácter comunal en relación al usufructo? ¿Hasta cuándo pervivió este carácter? ¿Qué transformaciones se produjeron entre el periodo colonial y el republicano?

En la bibliografía de corte histórico y antropológico ha existido la tendencia, matizada y reformulada por cierto en los últimos años, a pensar las comunidades (fundamentalmente las indígenas) como entes homogéneos y aconflictivos cuyos integrantes acceden equitativamente a los recursos (la tierra principalmente). En el caso de Colalao y Tolombón, López de Albornoz \& Bascary (1998) demostraron que a fines del siglo XVIII la comunidad presentaba marcados rasgos de estratificación social y acceso diferencial a los bienes. Esta diferenciación interna fue profundizándose en la segunda mitad del siglo XIX, cuando se inició el fraccionamiento de las tierras y tuvo su mayor punto de inflexión en 1903 cuando finalmente se produjo la división y adjudicación de las mismas. La división, compra-venta y desestructuración de la propiedad comunal de las tierras de Colalao y Tolombón han sido detalladamente descritas por Fandos (2007a) y Teruel \& Fandos (2009). Si bien este proceso es innegable, también es cierto que - a pesar de la estratificación y de los conflictosdesde el periodo colonial y durante gran parte del siglo XIX, la propiedad de las tierras de Colalao y Tolombón se mantuvo indivisa. Diversos mecanismos, probablemente resultantes de la experiencia de muchos años, se pusieron en marcha para resguardar el «bien común».

Uno de estos mecanismos pudo haber sido el de la designación de los apoderados, en tanto fue en estas figuras en quien debían «depositarse los intereses del pueblo». Ya se ha visto, a grandes rasgos, las funciones que cumplían los mismos. Fundamentalmente, la intermediación frente al Estado en cuestiones legales (principalmente en pleitos por tierras) y la administración de los bienes comunales. En relación a este último aspecto, el tema de los arriendos parece haber sido central. Existen registros de que el arrendamiento de las tierras colectivas se realizaba, al menos, desde fines del siglo XVIII48 y correspondía a las tierras más ricas en pastizales que, justamente, eran las que estaban en disputa. La cuestión de los arriendos no era un tema menor puesto que generaba un importante ingreso para la comunidad. El apoderado de Paz, en el juicio por las tierras y a propósito del pedido de eliminación de la figura del protector, decía que los terrenos arrendados les rendían a los indios:

«Más de trescientos pesos; los mismos que consumen en bebendurrias y otros vicios [...] esto prueba que nunca pueden ser [agraviados en esta parte] porque teniendo estos abundantes productos [...] pueden con él satisfacer desahogadamente el papel sellado [que usurpan] al estado y los derechos del escribano» 49 .

\footnotetext{
${ }^{48}$ Mata de López señala que a fines del siglo XVIII, y a fin de cubrir con las obligaciones fiscales ya en cabeza de su Majestad, los indios decidieron iniciar el arrendamiento «por ser muchas las tierras y pocos los indios» (Mata de López, 1991: 51). Agrega el dato de que hacia 1798 eran siete los arrenderos.

49 AHT, SJC, Caja 77, Expte. 1, Año 1840, fs.181v y 182.
} 
El tema de los arriendos era un punto clave y lo que se observa en los expedientes es que, además de la disputa por el terreno en sí, las partes forcejeaban por los arrenderos que se encontraban en dichas tierras. ¿A quién debían pagar? ¿A quién debían beneficiar con los testimonios? Los apoderados, desde el principio, han estado asociados a las tareas de arrendar, cobrar y distribuir los réditos entre los integrantes de la comunidad. Así, en una de las elecciones de apoderados realizada en 1845, se detallaban las funciones que estos debían cumplir:

«Que administren todos los negocios que tienen y tuvieran las dichas comunidades, arrienden los terrenos de ellas, perciban el precio y lo distribuyan a favor de las comunidades conforme a derecho, no consientan que ningún individuo de ellas cobren a ningún arrendero en particular por ser voluntad que todo entre en la masa común, que tampoco consientan que ningún individuo extraño pueda poblarse en los terrenos de ellas por contrato particular con alguno de los propietarios, pues para este caso, desde ahora, dan por nulo todo lo que al contrario se hiciese y que los apoderados puedan quitar a los arrenderos así introducidos, sus casas y poner en ellas a los que por bien tuvieren. Puedan obligar las propiedades de las comunidades para obtener algún dinero en caso por derecho necesario, cuando las comunidades de sus fondos no tuvieren y desobligarlas desde el momento en que los fondos de ellas tuvieren como hacerlo»50.

De la cita, que muestra claramente el rol de los apoderados en torno a la cuestión de los arriendos y a su distribución entre la «masa en común», se quiere destacar dos aspectos. Por un lado, el hecho de que la comunidad disponía de fondos que le eran propios. Una forma de obtenerlos era, lógicamente, a través del arriendo o, como vimos, a través de préstamos de pequeños montos de dinero solicitados a distintas personas vinculadas a la comunidad. En esta sintonía, aparece como interesante el hecho de que también los propios integrantes de la comunidad realizaban contribuciones extraordinarias (¿derramas?) para afrontar, por ejemplo, «los gastos de la cuestión del terreno con el cargo de devolvérselos de los fondos de arriendo» $\$ 5$. Por otro lado, y en estrecha relación al punto anterior, el hecho de que podían «obligar y desobligar» las propiedades de la comunidad en función de las necesidades monetarias. En relación con esto, se entiende que los apoderados tenían la facultad de prendar los terrenos (o parte de ellos) a través de una operación hipotecaria52. La asignación de esta función podría leerse como la antesala del fraccionamiento y posterior venta de las tierras. Este parece haber sido el caso de José Manuel Condori. Así, en 1852, se autorizó la venta de «una parte de terreno de esta estancia nombrada Colalao pero en los titu (sic) Ilamada

50 AHT, SJC, Caja 269, Expte. 9, Año 1845, fs. 5 y 5v.

51 AHT, SJC, Caja 80, Expte. 17, Año 1843, f. 29.

52 Para la década de 1870, ya iniciado el proceso de fraccionamiento de las tierras, Fandos (2007a) ha analizado varias operaciones de compra-venta que funcionaron como un medio de obtención de crédito. Aunque en estos casos, al seguir vigente la propiedad colectiva pero bajo la figura del condominio, quienes hipotecaban los terrenos eran personas individuales. 
Pusana para satisfacer compromisos de que esta tenía contraídos, en cuya virtud le damos en venta real y perpetua enajenación para siempre jamás a don José Manuel Condori» $>3$.

Un aspecto sobre el que prácticamente no se tiene registros es el que refiere a cómo se asignaban o distribuían las tierras entre los integrantes de la comunidad o si era el apoderado el encargado de tales tareas; tampoco se sabe si había similitudes en relación a las formas en que este tema se resolvía en épocas coloniales. Según uno de los expedientes consultados, el proceso para usufructuar las tierras comunales era simple y no estaba centralizado en una figura de autoridad. Al ser una propiedad colectiva, cada uno de los propietarios hacía «sus poblaciones a donde mejor le parece, no estando ocupado por otro»54. Esta aparente sencillez, por supuesto, podía traer problemas como el que se había desatado entre Mauricio Goya (hermano de Bernardo Goya) y Eusebio Córdoba (hijo de Mariano Córdoba). En 1860, Eusebio - a través del ministerio de pobres—-denunciaba a Mauricio por ocupar un pedazo de terreno sin título de propiedad, que le pertenecía a Eusebio por haberlo heredado de sus padres. Mauricio respondía a la acusación diciendo que el terreno era parte de la estancia de Colalao, la cual — todavía indivisa— era de varios propietarios entre los que él se contaba. Agregaba que los padres de Córdoba habían ocupado el terreno en disputa pero que a su muerte, y habiendo quedado el lugar abandonado, él se había posesionado del mismo. Una vez más, las reyertas entre Córdobas y Goyas permiten dimensionar las tensiones emergentes, en este caso, alrededor del problema de la tierra en un periodo de profundas transformaciones. Es posible pensar, a partir de lo señalado, que la idea de una propiedad colectiva y el derecho al usufructo por cualquiera de sus propietarios estaba entrando en contradicción con el proceso ya iniciado de fraccionamiento y privatización de la propiedad colectiva de la estancia de Colalao.

\section{A MODO DE REFLEXIÓN FINAL}

Así como Farberman (2001) señalaba las dificultades que como investigadores tenemos en asir y comprender el funcionamiento de los pueblos de indios tardocoloniales, también se encuentra aquí, por la naturaleza misma de nuestra unidad de análisis, serios problemas para definir y entender las características de la comunidad de Colalao y Tolombón en un periodo de cambios profundos como lo es el de las primeras décadas del nuevo orden republicano. De esta manera, aunque ya a fines del siglo XVIII se produjeron — de la mano de los Borbonesimportantes transformaciones que impactaron sobre las poblaciones indígenas y en particular sobre los pueblos de indios, se entiende que las mismas se ahondaron en la primera mitad del siglo XIX.

Como se observa en nuestro caso de análisis, los antiguos pueblos de Colalao y Tolombón —que a fines del siglo XVIII ya estaban integrados por migrantes

\footnotetext{
53 AHT, SJC, Caja 220, Expte. 17, Año 1876, f. 3 y 3v. El destacado es nuestro.

54 AHT, SJC, Caja 263, Expte. 5, f. 2.
} 
de diversos lugares, indios forasteros sin tierras, mulatos y zambos, entre otrosmantuvieron y reforzaron esta apertura a través de la incorporación de distintos individuos de variados status étnicos y socioeconómicos. Aunque los mecanismos de incorporación no quedan claros (probablemente el casamiento haya sido uno de los más importantes), lo que sí parece desprenderse de nuestros datos es que a partir de las nuevas políticas e ideas liberales una nueva organización comunal, más asociativa o voluntarista, se estaba poniendo en marcha. Probablemente, la indefinición jurídica en la que quedaron los indígenas, la eliminación del tributo y la atenuación de la marca fiscal y étnica que esto suponía hayan facilitado la porosidad de los límites de la comunidad, profundizando la tendencia (presente en todo el periodo colonial y agudizada hacia fines del mismo) de integrar en su interior a variadas personas y escapar de los márgenes legales. Es que la definición de lo que es un «pueblo de indios» y luego una «comunidad», incluye o parte de marcos que refieren a lo institucional y/o jurídico pero que, a la vez, son redefinidos y tensionados a partir de las prácticas e interpretaciones de los sujetos. Aunque aún es necesario profundizar en esta línea, se cree que los marcos jurídicos coloniales pudieron haber sido más rígidos en relación con los indígenas que aquellos desplegados en las primeras décadas republicanas.

En sintonía con este aspecto, es interesante la perspectiva planteada por Jacobsen (1997) quien muestra que las ideas liberales, lejos de predeterminar un único y trágico destino para las comunidades indígenas de Perú en las décadas siguientes a la independencia, constituyeron nuevos peligros pero también nuevas oportunidades. Las ideas liberales encontraron diferentes grados de aceptación no solo entre distintas comunidades, sino incluso al interior de cada una de ellas (tal como parece ser nuestro caso) pero, en líneas generales:

«The liberal stress on property rights, citizenship, and free association allowed dynamic groups of peasants to push for recognition of their own rights before the nation's courts and other authorities... The combination of their ancient communitarian traditions, derived both from Andean pre-Hispanic civilization and Spanish colonial corporatism, with emancipatory aspects of liberalism allowed Peru's peasant communities to confront relatively successfully the ongoing challenges of nation-state formation and capitalist market penetration. This has been a painful, slow, and contradictory process, filled with losses and victories for the Andean peasantry» (Jacobsen, 1997: 160).

Tal como se señala en la cita, estos procesos no fueron sencillos, lineales o libres de tensión. En el caso de Colalao y Tolombón, como bien lo ha descrito Fandos (2007a), los conflictos se expresaron en la disputa por tierras con los sectores más poderosos y encumbrados de la zona pero, también, al interior de la propia comunidad. En ese sentido, es ilustrativo el ejemplo de Bernardo Goya y Mariano Córdoba, quienes no solo presentaban trayectorias personales o familiares, étnicas y sociales diferentes, sino que podrían verse como representantes de dos formas divergentes de entender y encarnar el destino que debía seguir la comunidad. Así, en torno al pleito desatado cuando Goya pidió remoción de Córdoba del cargo de apoderado, se debate tanto la cuestión de quién conforma la comunidad o es un 
integrante legítimo o ilegítimo de la misma como la forma en que la comunidad será o debería ser representada.

La figura del apoderado resulta significativa y característica de este periodo de transición y de los cambios asociados a él. Por un lado, porque como en Bolivia, una de las misiones de los apoderados parece haber sido la de «la lucha legal por el mantenimiento del status corporativo a partir de las bases territoriales heredadas de la Colonia» (Mendieta Parada, 2006: 763). Sin embargo, como se ha visto en nuestro caso de análisis, si bien los apoderados aparecen como los representantes $y$, de alguna forma, un mecanismo de resguardo de los «derechos del cuerpo» son, a la vez, tanto el resultado como los promotores o artífices de las transformaciones. Por otro lado, y en relación con lo anterior, porque se constituyen en figuras polémicas que, entre otras cosas, empezarán a detentar cierto poder al funcionar como intermediarios y administradores de los bienes de la comunidad. Aunque no disponemos de información acerca de si tuvieron injerencia en la distribución de la tierra entre los integrantes de la comunidad, sí se sabe que se ocuparon de uno de los temas más importantes asociados a la misma: el de los arriendos. Manejaron, asimismo, la caja de la comunidad y tuvieron el poder de «obligar» y «desobligar» la propiedad comunal cuando así hiciera falta. Este último aspecto, en particular, resulta elocuente y significativo en tanto podría constituir un elemento más de análisis para comprender el proceso por el cual la propiedad comunal finalmente se fraccionó y privatizó.

Ahora bien, hasta aquí se ha hecho un repaso de algunos aspectos trabajados a lo largo de este texto en relación a las características - conflictivas, contradictorias y en evidente transformación — que adquirió la comunidad de Colalao y Tolombón durante la primera mitad del siglo XIX. Pero, en definitiva, ¿qué era la comunidad? ¿Por qué existía? Volvamos a la discusión inicial entre el apoderado de Juana Cornejo y del protector de los naturales de Colalao y Tolombón.

Los apoderados de Juana Cornejo y luego de Manuel Paz argumentaban que la comunidad ya no existía porque el tributo y las mitas, los encomenderos y los caciques habían sido eliminados. El protector de naturales argüía que esto era cierto y evidente pero que, sin embargo, los terrenos de la comunidad todavía estaban indivisos y, por lo tanto, la misma se mantenía vigente. De alguna forma, ambas partes delineaban las características que debía tener o no una comunidad en relación a cómo se definía un pueblo de indios en época colonial. Como señala De la Orden (2006), los requisitos para que un pueblo de indios fuera legalmente reconocido como tal eran tres: un conjunto de indígenas tributarios, una estructura política y tierras comunales. Así, los apoderados de Cornejo y de Paz hacían hincapié en dos elementos fundamentales de la constitución de los pueblos de indios (tributos y caciques) para negar su existencia, mientras que el defensor de naturales remarcaba la permanencia de la propiedad colectiva de la tierra y por ende de la comunidad. En definitiva, los argumentos de ambas partes eran parcialmente correctos.

En relación a esto, podemos preguntarnos: ¿A mediados del siglo XIX es la comunidad como institución la heredera de los antiguos pueblos de indios? ¿O 
se trata de una entidad totalmente nueva? De alguna manera, la respuesta a estas preguntas está implícita en la forma en que estructuramos este texto. El lector notará que los tres apartados centrales del mismo coinciden en parte con los tres elementos definitorios de los pueblos de indios, por lo tanto - a nuestro entender - son innegables ciertas continuidades. Sin embargo, a la luz de los datos aquí expuestos también se observa que, en el siglo XIX, la comunidad solo coincidía parcialmente con lo que era el antiguo pueblo de indios. El caso de Colalao y Tolombón muestra, entonces, que la comunidad —en parte heredera de los designios coloniales y en parte resultado de los cambios producidos por el nuevo orden- era una institución en redefinición que constituía una entidad jurídica, definida por el carácter comunal de la tierra pero también por la voluntad de sus integrantes de asociarse (a pesar de los conflictos y las disidencias) y organizarse en torno a la misma.

Según Mossbrucker (1990), las características que definen a una comunidad son tres: a) que se encuentra ligada a recursos económicos determinados; b) que administra esos recursos; y, c) que la cantidad de familias que la componen se encuentra en relación directa con el volumen y significado económico de los recursos controlados y con los intereses de estos miembros. Advierte, asimismo, que la comunidad no preexiste a sus integrantes y que «[p]or consiguiente, las comunidades deben entenderse en primer lugar como expresiones institucionales de asociaciones de familias, que a través de ellas quieren solucionar problemas y hacer prevalecer intereses determinados» (Mossbrucker, 1990: 98). Esta definición permite entender que las comunidades como institución pueden ser reestructuradas e incluso, como dice el autor antes citado, refundadas por sus miembros. Ahora bien, ¿de qué depende esta voluntad de asociarse? Según Mossbruker son las condiciones socioeconómicas las que llevan a los individuos a organizarse en tales instituciones. Si bien acordamos con esta postura, pensamos que habría que sumar a este planteo un elemento más de análisis: la cuestión de las identidades colectivas y las relaciones de poder en las que históricamente se enmarcan. Por supuesto, la incorporación de la dimensión identitaria requeriría de un mayor análisis y excede por mucho el objetivo del artículo. Sin embargo, entendemos, que la misma acompaña y se interpenetra dialécticamente con las transformaciones económicas, políticas e institucionales. Así, la incorporación de personas que se diferenciaban socioétnicamente del resto pero que, a la vez, estaban integradas a la entidad; la eliminación de las antiguas figuras de autoridad y la aparición de los apoderados y, fundamentalmente, el lento proceso de fragmentación y privatización de las tierras colectivas que se describe hacia el último cuarto del siglo XIX, seguramente implicaron o estuvieron asociados a una redefinición de la identidad colectiva.

En definitiva, todos estos procesos de cambios desarrollados a lo largo del siglo XIX y enmarcados en una serie de políticas de corte liberal, constituyeron —en especial para las comunidades de origen étnico indígena - «a crucial historical experience for their continued vitality until today» (Jacobsen, 1997: 160). En nuestro país, restan aún estudios que permitan mapear y caracterizar esa experiencia histórica crucial por la que atravesaron las comunidades indígenas y los destinos que cada 
una de ellas forjó, entendiendo que se trata de procesos dinámicos basados en las acciones y en las experiencias de los sujetos involucrados, enmarcados en relaciones de poder (también históricamente determinadas) y que implicaron una serie de redefiniciones a distintos niveles: socioeconómico, político, identitario, jurídico institucional. Esperamos, con el análisis del caso de la comunidad de Colalao y Tolombón, haber contribuido en tal sentido.

\section{Referencias citadas}

\section{Fuentes primarias}

Archivo General de la Nación argentina (AGN)

Revisita de San Miguel de Tucumán, Años 1786 y 1792, Sala XIII 17-2-1, Leg. 2, Libros 3 y 6 .

Revisita de San Miguel de Tucumán, 1806, Documentos Diversos, Leg. 32.

Archivo Histórico de Tucumán (AHT)

Sección Administrativa (SA), Vol. 40, Tomo II, Año 1832.

Sección Judicial Civil (SJC), Caja 290, Expte. 1, Año 1839.

SJC, Caja 77, Expte. 1, Año 1840.

SJC, Caja 80, Expte. 17, Año 1843.

SJC, Caja 269, Expte. 9, Año 1845.

SJC, Caja 88, Expte. 20, Año 1849.

SJC, Caja 93, Expte. 3, Año 1855.

SJC, Caja 263, Expte. 5, Año 1860.

SJC, Caja 220, Expte. 17, Año 1876.

Sección Judicial Criminal (SJCr), Caja 56, Expte. 6, Año 1832.

Archivo Parroquial de Trancas (APT)

Libros de Matrimonios, Vols. IV, V y VII.

\section{Fuentes secundarias}

COSAMALÓN AGUILAR, J., 1999 - Indios detrás de la muralla. Matrimonios indígenas y convivencia inter-racial en Santa Ana (Lima, 1795-1820), 274 pp., Lima: PUCP.

DE LA ORDEN, G., 2006 - Pueblos indios de Pomán. Catamarca (siglos XVII a XIX), 158 pp.; Buenos Aires: Editorial Dunken.

DOUCET, G., 1993 - La abolición del tributo indígena en las Provincias del Río de la Plata: indagaciones en torno a un tema mal conocido. Revista del Derecho, 21: 133-207. 
FANDOS, C., 2007a - Estructura y transferencia de la propiedad comunal de Colalao y Tolombón (provincia de Tucumán) en la segunda mitad del siglo XIX. Mundo Agrario. Revista de estudios rurales, 14. Disponible en: http://www.mundoagrario. unlp.edu.ar

FANDOS, C., 2007b - La Comunidad indígena de Colalao (Tucumán) en la segunda mitad del siglo XIX, vínculos y estrategias, el caso Guaisman. Ponencia presentada en Primeras Jornadas Nacionales de Historia Social; Córdoba: Centro de Estudios Históricos «Profesor Carlos S. A Segreti».

FARBERMAN, J., 2001 - Los matrimonios de Soconcho. Endogamia, tierra y comunidad en tres pueblos de indios de Santiago del Estero. 1750-1809. Memoria Americana. Cuadernos de Etnohistoria, 10: 43-65.

FARBERMAN, J., 2005 - Curacas, mandones, alcaldes y curas. Legitimidad y coerción en los pueblos de indios de Santiago del Estero, siglos XVII y XVIII. Actas del VI Congreso Internacional de Etnohistoria; Buenos Aires: Universidad de Buenos Aires.

GARRIDO, H., 2005 - Población y tierra en la cuenca de Trancas, provincia de Tucumán (República Argentina). Cuadernos de Desarrollo Rural, 54: 31-60.

GIL MONTERO, R., 2002 - Tierras y tributo en la puna de Jujuy. Siglos XVIII y XIX. In: Los pueblos de indios del Tucumán colonial: pervivencia y desestructuración (J. Farberman \& R. Gil Montero, eds.): 227-255; Buenos Aires: UNQ Ediciones, EDIUNJu.

GIL MONTERO, R., 2008 - La construcción de Argentina y Bolivia en los Andes Meridionales. Población, tierras y ambiente en el siglo XIX, 282 pp.; Buenos Aires: Prometeo.

JACOBSEN, N., 1997 - Liberalism and indian communities in Perú, 1821-1920. In: Liberals, the Church and Indian Peasants: corporate lands and the challenge of reform in nineteenth-century Spanish America (R. H. Jackson, ed.): 123-170; Alburquerque: University of New Mexico Press.

LEVAGGI, A., 1990 - Tratamiento legal y jurisprudencial del aborigen en la Argentina durante el siglo XIX. In: El Aborigen y el Derecho en el pasado y el presente (A. Levaggi, coord.): 245-285; Buenos Aires: Universidad del Museo Social Argentino.

LÓPEZ, C., 2006 - Tierras comunales, tierras fiscales: el tránsito del orden colonial a la revolución. Revista Andina, 43: 215-238.

LÓPEZ DE ALBORNOZ, C. \& BASCARY, A. M., 1998 - Pueblos indios de Colalao y Tolombón: identidad colectiva y articulación étnica y social (siglos XVII-XIX). Humanitas. Revista de la Facultad de Filosofía y Letras, 27: 71-112.

LORANDI, A. M. \& BOIXADÓS, R., 1987-1988 - Etnohistoria de los valles Calchaquíes en los siglos XVI y XVII. Runa, 17-18: 263-419.

MACÍAS, F., 2007 - Armas, milicias y Comandantes. La configuración del Poder Ejecutivo y del Ejército Provincial en la primera mitad del siglo XIX (1832-1852). Disponible en: www.historiapolitica.com/datos/biblioteca/macias1.pdf

MATA DE LÓPEZ, S., 1991 - Estructura agraria. La propiedad de la tierra en el valle de Lerma, valle Calchaquí y la frontera este (1750-1800). Andes. Antropología e Historia, 1: 47-88.

MENDIETA PARADA, P., 2006 - Caminantes entre dos mundos: los apoderados indígenas en Bolivia (siglo XIX). Revista de Indias, LXVI (28): 761-782.

MOSSBRUCKER, H., 1990 - La economía campesina y el concepto de «comunidad»: un enfoque crítico, 115 pp.; Lima: Instituto de Estudios Peruanos.

O'PHELAN GODOY, S., 1997 - Kurakas sin sucesiones. Del cacique al alcalde de indios. Perú y Bolivia 1750-1835, 100 pp.; Cuzco: Centro de Estudios Regionales Andinos Bartolomé de Las Casas. 
RODRÍGUEZ, L., 2009 - Los usos del sistema judicial, la retórica y la violencia en torno a un reclamo sobre tierras comunales. Amaicha del Valle, siglo XIX. Runa, 30 (2): 135-150.

SALA I VILA, N., 1992-1993 - La constitución de Cádiz y su impacto en el gobierno de las comunidades indígenas en el virreinato del Perú. Boletín Americanista, 42-43: 51-70.

SERULNIKOV, S., 2004 - Legitimidad política y organización social en las comunidades indígenas de la provincia de Chayanta (siglo XVIII). Anuario de Estudios Americanos, 61 (1): 69-101.

SOUX, M. L., 2005 - Jueces pedáneos, jilaqatas apoderados y otros articuladores de la justicia local entre colonia y república. Actas del VI Congreso Internacional de Etnohistoria; Buenos Aires: Universidad de Buenos Aires.

TELL, S., 2010 - Expansión urbana sobre tierras indígenas. El pueblo de La Toma en la Real Audiencia de Buenos Aires. Mundo Agrario, 10 (20). http://www.mundoagrario. unlp.edu.ar

TERUEL, A. \& FANDOS, C. 2009 - Procesos de privatización y desarticulación de tierras indígenas en el norte de Argentina en el siglo XIX. Revista Complutense de Historia de América, 35: 233-255.

WACHTEL, N., 2001 - El regreso de los antepasados. Los indios urus de Bolivia del siglo XX al XVI. Ensayo de historia regresiva, 644 pp.; México D. F.: Fondo de Cultura Económica. 